\title{
Eli Murlakov
}

\section{Das Recht der Völker auf Selbstbestimmung im israelisch-arabischen Konflikt}

Diss. Zürich, Schweizer Studien zum internationalen Recht, Band 31, Schulthess Polygraphischer Verlag, Zürich, 1983, 162 S., 36 sfr.

In seiner Arbeit vergleicht der Autor die nationalen Ansprüche von Israelis und Palästinensern und versucht, eine Lösung für die Frage zu finden, wie die politischen Bestrebungen dieser Völker verwirklicht werden können.

Zunächst geht Murlakov auf die theoretischen Grundlagen des Selbstbestimmungsrechts ein, wobei er angesichts der großen Unsicherheiten bei diesem Begriff starke Bedenken gegen dessen Rechtsqualität hat. Murlakov versucht durch eine Aufstellung der wesentlichen Elemente eines Selbstbestimmungsvorgangs klare Kriterien herauszuarbeiten. Träger des Selbstbestimmungsrechts könne nur ein Volk sein. Was darunter zu verstehen ist, müsse für jeden Einzelfall geprüft werden, wobei sowohl auf objektive (z. B. Sprache, Abstammung, Kultur) als auch auf subjektive Elemente (Zusammengehörigkeitsgefühl) abzustellen sei. Ferner sei ein rechtmäßiger Anspruch auf ein bestimmtes Territorium erforderlich. Für ein im Exil lebendes Volk müsse ein besonderer Bezug zum beanspruchten Gebiet vorliegen, der sich in der seelischen Verbundenheit und der historischen Verwurzelung des Volkes zu seiner Heimat äußern könne. Dabei dürfe bezüglich des betroffenen Gebietes kein gültiger Rechtstitel eines anderen Volkes vorliegen. Weitere Voraussetzungen des Selbstbestimmungsrechts seien die Selbstbestimmungsfähigkeit, ein kollektiver Selbstbestimmungsentscheid und eine repräsentative politische Organisation. Am Ende des Vorgangs stehe eine den Staat formell erschaffende Verfassung. Sind diese Voraussetzungen erfüllt, solle eine Pflicht bestehen, das Recht des Volkes auf einen eigenen Staat anzuerkennen. Eine gewaltsame Durchsetzung des Anspruchs sei unzulässig, solange nicht alle anderen Möglichkeiten zur Durchsetzung ausgeschöpft seien und solange nicht ein Plebiszit herbeigeführt worden sei.

Diese theoretischen Uberlegungen überträgt der Autor auf die konkrete Situation des israelischen und des palästinensischen Volkes. Er skizziert zunächst die Geschichte des jüdischen Volkes und die Entstehung des Staates Israel, wobei er alle Voraussetzungen für das Selbstbestimmungsrecht als erfüllt ansieht. Das jüdische Volk sei durch gemeinsame Religion, Vergangenheit, Sprache und Kultur auch in der Diaspora erhalten geblieben, was sich im Zusammengehörigkeitsgefühl äußere. Das historische und natürliche Recht der Juden auf "Eretz Israel" folge aus der geschichtlichen Verbundenheit mit Palästina, was durch den UN-Teilungsbeschluß von 1947 bestätigt würde. Die Selbstbestimmungsfähigkeit sei vorhanden, ein kollektiver Selbstbestimmungsentscheid war überflüssig, da es sich um die Wiederherstellung jüdischer Souveränität handelte, die zunehmende Besiedlung Palästinas durch Juden ein eindeutiges Votum darstellte und eine Volksbefragung unter der englischen Mandatsherrschaft kaum möglich war. Die Jewish Agency war eine repräsentative politische Organisation, Israel ist durch die Unabhängigkeitserklärung von 1948 konstituiert worden, die Souveränität liege bei der jüdischen Bevölkerung. Israel ist von den meisten Staaten völkerrechtlich anerkannt 
worden, lediglich von den arabischen Staaten mit Ausnahme Ägyptens nicht. Der Autor geht auf mehrere Gegenargumente gegen das Selbstbestimmungsrecht des jüdischen Volkes ein, verwirft sie jedoch alle. Auch die Teilung Palästinas widerspreche nicht dem Selbstbestimmungsrecht der Völker, obwohl die Mehrheit der palästinensischen Bevölkerung nach arabischer Ansicht gegen die Teilung gewesen sei und kein Plebiszit stattgefunden habe. Der UN-Teilungsplan von 1947 entspreche gerade deshalb dem Selbstbestimmungsrecht der Völker, weil er der Existenz zweier Völker in Palästina Rechnung getragen habe.

Anschließend an das israelische untersucht der Autor das palästinensische Recht auf Selbstbestimmung. Er beschreibt das Entstehen des palästinensischen Nationalismus und erkennt an, daß die Palästinenser aufgrund nachweisbarer Gemeinsamkeiten und eines seit 1967 verstärkten Einheitsbewußtseins ein Volk bilden. Die Palästinenser würden in der Gegenwart politisch durch die PLO vertreten, die trotz innerer Zerwürfnisse die mächtigste und einflußreichste Organisation sei. Der territoriale Anspruch der PLO bezieht sich auf ganz Palästina einschließlich des jetzigen Staatsgebiets Israels. Murlakov verneint jedoch die Selbstbestimmungsfähigkeit des palästinensischen Volkes, da es über keine akzeptable politische Organisation verfüge. Die PLO sei solange nicht akzeptabel, wie sie nicht die Existenz Israels anerkenne und terroristische Akte verurteile und beende. Dies gelte trotz der wachsenden völkerrechtlichen Anerkennung der PLO. Hier fordern die Ausführungen Murlakovs am ehesten zum Widerspruch heraus. Zwar ist der Verurteilung jeder Gewalt zuzustimmen, es ist aber fraglich, ob deshalb das Selbstbestimmungsrecht der Palästinenser blockiert ist und die PLO als Verhandlungspartner für Israel absolut ausscheidet, zumal gewalttätige Auseinandersetzungen gerade durch Verhandlungen am ehesten beendet werden könnten. Der Autor mag zwar mit seiner Behauptung Recht haben, die Kompromißlosigkeit der PLO verzögere den Selbstbestimmungsvorgang des palästinensischen Volkes, die israelische Auffassung, die der Autor in der Ablehnung eines selbständigen palästinensischen Staates, der PLO und der Teilung Jerusalems zusammenfaßt, ist aber ähnlich kompromißlos.

Zuzustimmen ist hingegen dem Fazit Murlakovs, daß grundsätzlich nationale Rechte des israelischen und des palästinensischen Volkes parallel nebeneinander bestehen. Kein Recht sei privilegiert. Eine Verwirklichung beider Rechte sei nur bei gegenseitiger Anerkennung möglich und nur bei Frieden und Entspannung im ganzen Nahen Osten. Insgesamt handelt es sich um ein Buch, das das Kernproblem des Nahostkonflikts deutlich herausarbeitet, selbst aber keine konkreten Lösungsvorschläge enthält.

Martin Buchholz 